\title{
Remnant cholesterol and risk of ischemic stroke in 112,512 individuals from the general population
}

Anette Varbo ${ }^{1,2,3}$, MD, PhD, and Børge G. Nordestgaard1,2,3,4, MD, DMSc.

${ }^{1}$ The Copenhagen General Population Study and ${ }^{2}$ Department of Clinical Biochemistry, Herlev and Gentofte Hospital, Copenhagen University Hospital; ${ }^{3}$ Faculty of Health and Medical Sciences, University of Copenhagen, Denmark; ${ }^{4}$ The Copenhagen City Heart Study, Frederiksberg Hospital, Copenhagen University Hospital, Denmark.

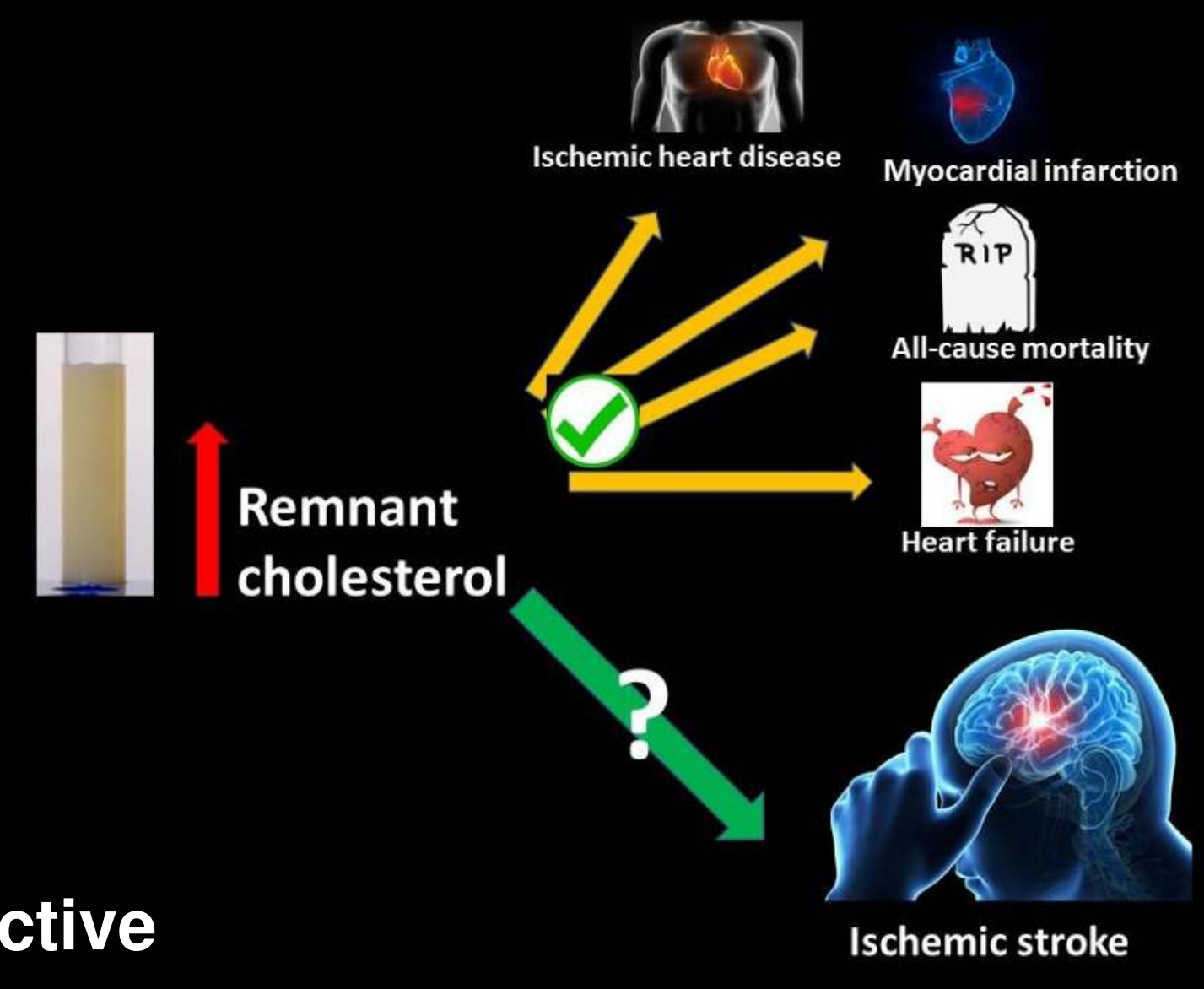

High remnant cholesterol is associated with cardiovascular disease risk. We tested the hypothesis that high remnant cholesterol is also associated with increased risk of ischemic stroke in the general population.

Copenhagen General Population Study (N = 102,964) Risk of ischemic stroke

\begin{tabular}{lllr}
$\begin{array}{l}\text { Remnant } \\
\text { cholesterol } \\
\text { mmol/L }\end{array}$ & $\begin{array}{c}\text { Mg/dL } \\
\text { total }\end{array}$ & \multicolumn{1}{c}{$\begin{array}{c}\text { N } \\
\text { events }\end{array}$} \\
$<0.5$ & $<19$ & 35,583 & 613 \\
$0.5-0.99$ & $19-38$ & 46,380 & 1,214 \\
$1-1.49$ & $39-58$ & 15,042 & 456 \\
$\geq 1.5$ & $\geq 58$ & 5,959 & 205
\end{tabular}

Multivariable adjusted

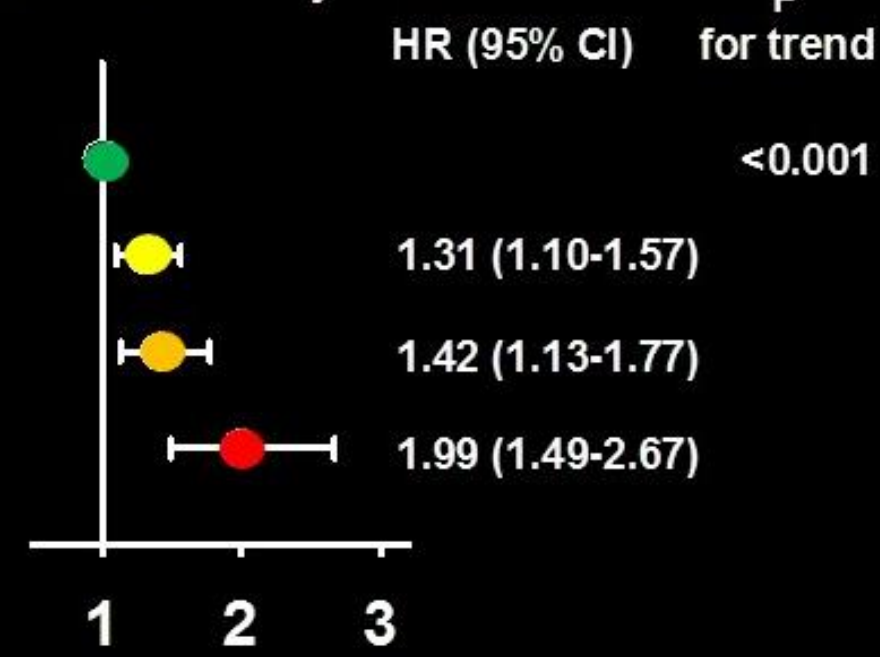

Copenhagen City Heart Study $(\mathrm{N}=\mathbf{9 , 5 4 8 )}$

$\mathrm{mmol} / \mathrm{L} \mathbf{~ m g} / \mathrm{dL}$

$<0.5<19 \quad 2,587 \quad 193$

0.5-0.99 $\quad 19-38 \quad 4,635 \quad 500$

$1-1.49 \quad 39-58 \quad 1,601 \quad 194$

$\geq 1.5 \quad \geq 58 \quad 725 \quad 96$

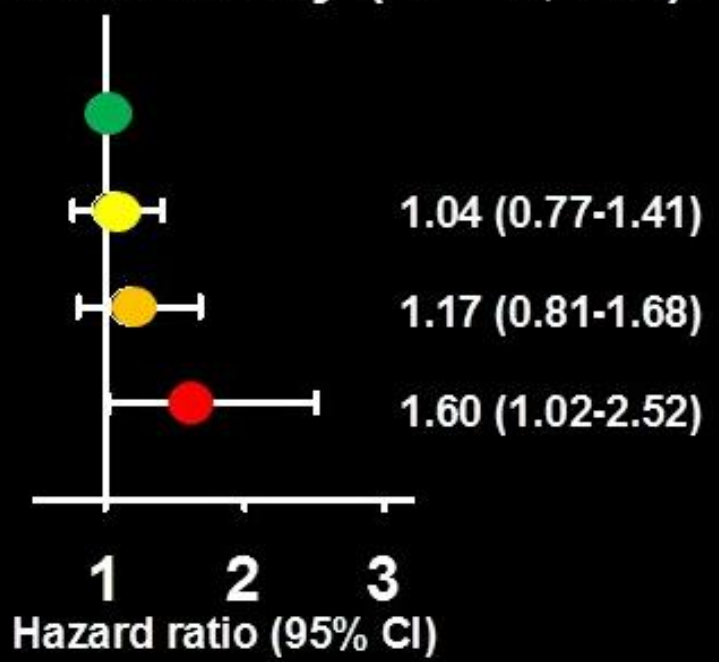

0.048

Hazard ratio $(95 \% \mathrm{Cl})$

Figure 2:

Hazard ratios estimated by Cox proportional hazard regression models showed stepwise higher risk of ischemic stroke for stepwise higher remnant cholesterol concentrations.

Results were independently confirmed in 9,548 individuals from the Copenhagen City Heart Study 1991-94 examination with 983 ischemic strokes developed during up to 26 years of follow-up.

\section{Conclusion}

High remnant cholesterol concentrations were associated with higher risk of ischemic stroke.

This indicates that randomized clinical trials with remnant cholesterol lowering in individuals with high concentrations, with the aim of preventing ischemic strokes, are needed.

\section{Copenhagen General Population Study}

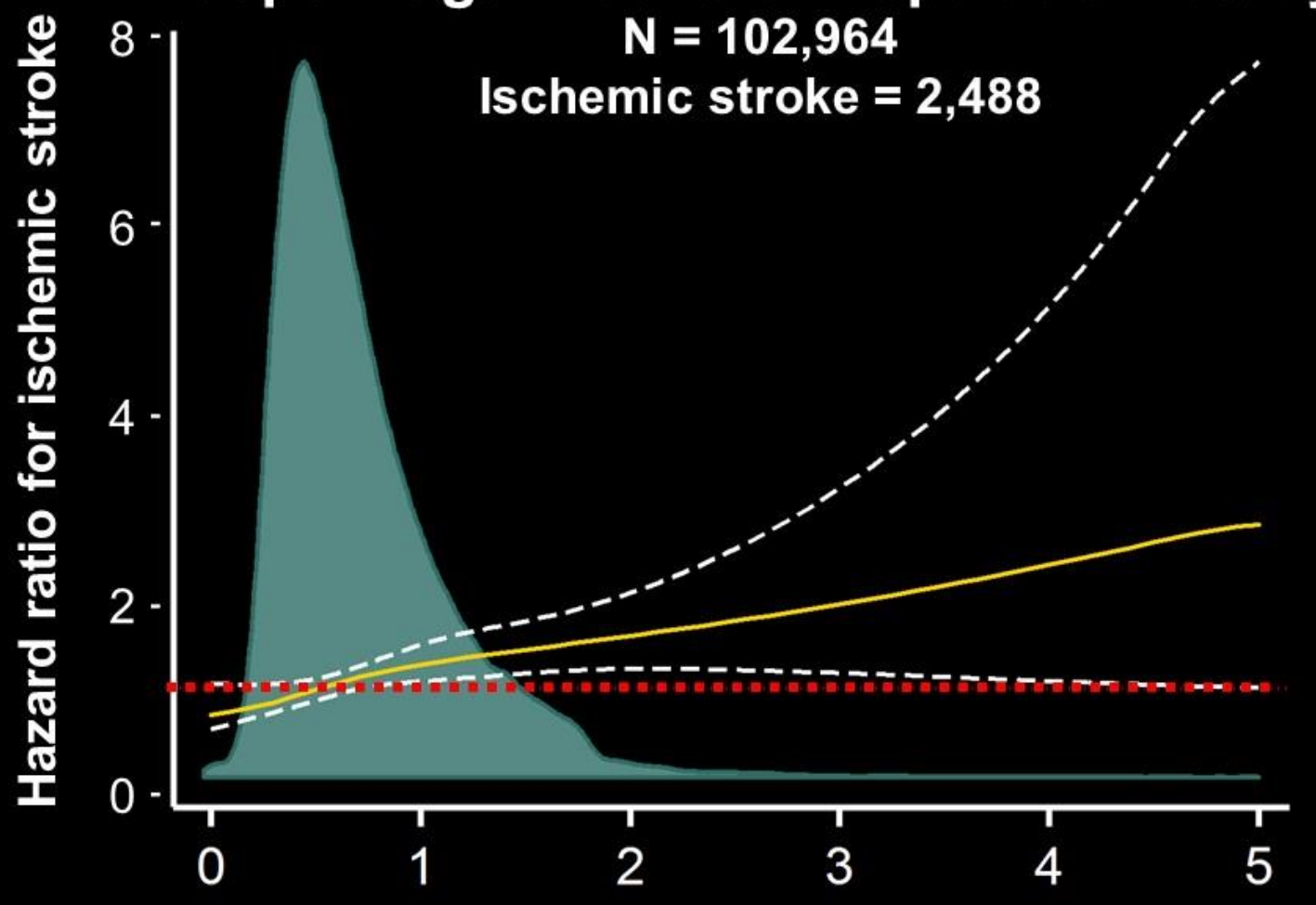

Remnant cholesterol, $\mathrm{mmol} / \mathrm{L}$

Figure 1:

102,964 individuals from the Copenhagen General Population Study 20032015 were included in a prospective observational association study. Individuals were followed for up to 14 years, during which time 2,488 were diagnosed with an ischemic stroke.

Using Cox regression restricted cubic splines, higher remnant cholesterol concentrations were associated with higher ischemic stroke risk.

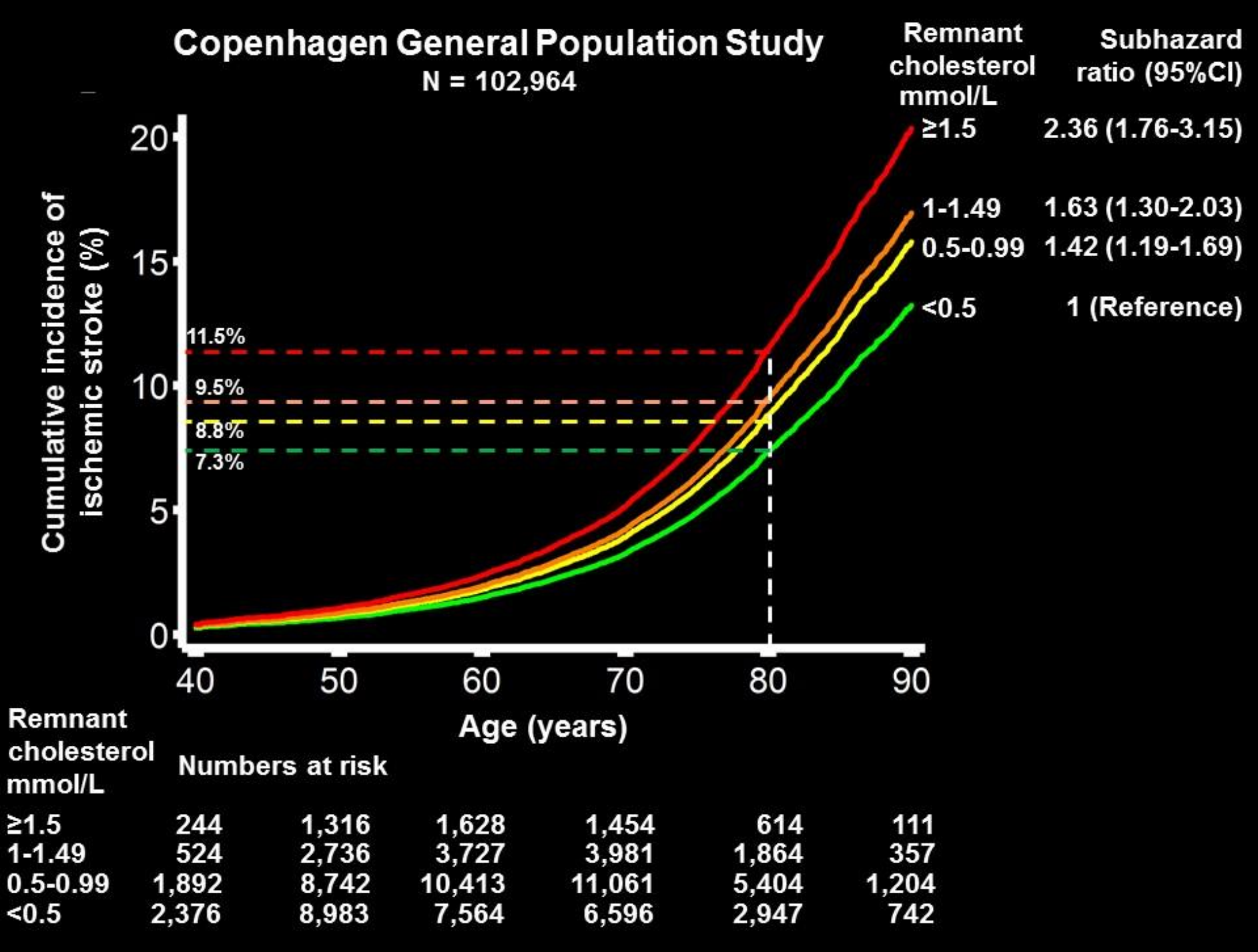

Figure 3:

In the Copenhagen General Population Study, cumulative incidence of ischemic stroke at age 80 ranged from $7.3 \%$ for individuals with remnant cholesterol $<0.5 \mathrm{mmol} / \mathrm{L}(19 \mathrm{mg} / \mathrm{dL})$ to $11.5 \%$ for individuals with remnant cholesterol $\geq 1.5 \mathrm{mmol} / \mathrm{L}(58 \mathrm{mg} / \mathrm{dL})$.
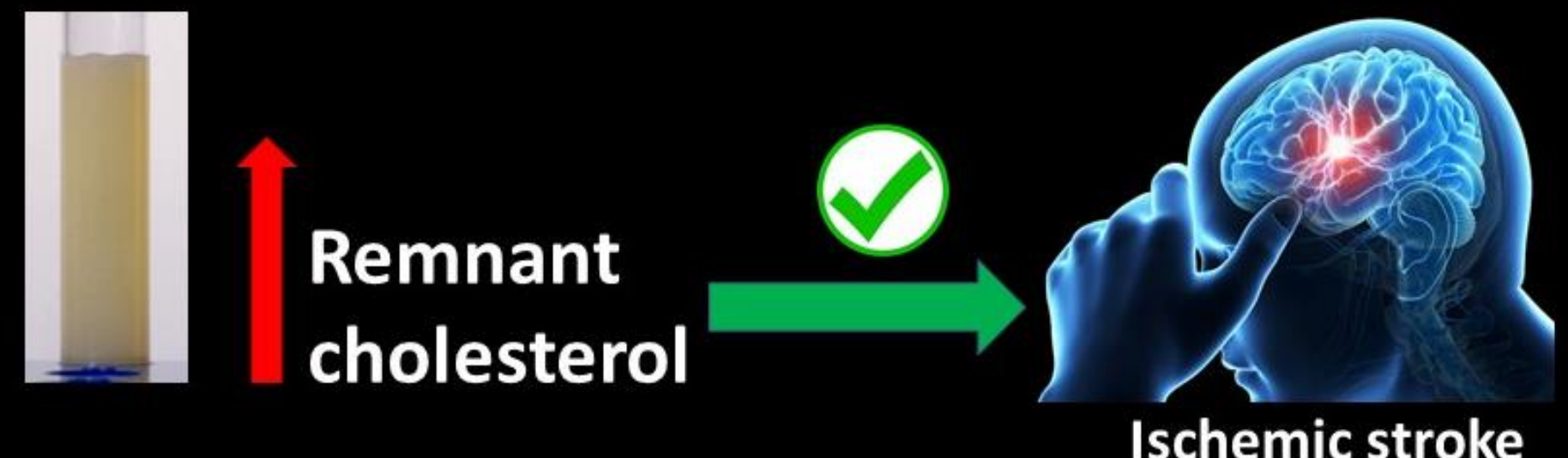